\title{
Pulmonary reinterventions after complete unifocalization and repair in infants and young children with tetralogy of Fallot with major aortopulmonary collaterals
}

Holly Bauser-Heaton, MD, PhD, ${ }^{a}$ Alejandro Borquez, MD, ${ }^{a}$ Ritu Asija, MD, ${ }^{\text {a }}$ Lisa Wise-Faberowski, MD, ${ }^{b}$ Yulin Zhang, PhD, ${ }^{\mathrm{c}}$ Laura Downey, MD, ${ }^{\mathrm{b}}$ Stanton B. Perry, MD, ${ }^{\mathrm{a}}$ Andrew Koth, MD, ${ }^{\mathrm{a}}$ Lynn F. Peng, MD, ${ }^{\mathrm{a}}$ Claudia A. Algaze, MD, MPH, ${ }^{\mathrm{a}}$ Frank L. Hanley, MD,${ }^{\mathrm{c}}$ and Doff B. McElhinney, $\mathrm{MD}^{\mathrm{a}, \mathrm{c}}$

\section{ABSTRACT}

Background: Our institutional approach to tetralogy of Fallot (TOF) with major aortopulmonary collaterals (MAPCAs) emphasizes unifocalization and augmentation of the reconstructed pulmonary arterial (PA) circulation and complete intracardiac repair in infancy, usually in a single procedure. This approach yields a high rate of complete repair with excellent survival and low right ventricular (RV) pressure. However, little is known about remodeling of the unifocalized and reconstructed pulmonary circulation or about reinterventions on the reconstructed PAs or the RV outflow tract conduit.

Methods: We reviewed patients who underwent complete repair of TOF with MAPCAs at our center at $<2$ years of age, either as a single-stage procedure or after previous procedures. Outcomes included freedom from conduit or PA intervention after repair, which were assessed by Cox regression and Kaplan-Meier analysis.

Results: The study cohort included 272 patients. There were 6 early deaths and a median of follow-up of 3.6 years after complete repair. Reinterventions on the pulmonary circulation were performed in 134 patients, including conduit interventions in $101 \mathrm{pa}-$ tients, branch PA interventions in 101, and closure of residual MAPCAs in 9. The first conduit reintervention consisted of surgical conduit replacement in 77 patients, transcatheter pulmonary valve replacement with a Melody valve in 14, and angioplasty or bare metal stenting in 10. Surgical PA reinterventions were performed in 46 patients and transcatheter reinterventions in 75 (both in 20). Most PA reinterventions involved a single lung, and most transcatheter reinterventions a single vessel. Freedom from conduit replacement or transcatheter pulmonary valve replacement was $70 \pm 3 \%$ at 5 years and was shorter in patients with smaller initial conduit size. Freedom from any PA reintervention was $64 \pm 3 \%$ at 5 years, with the greatest rate during the first year. On multivariable analysis, factors associated with longer freedom from any PA reintervention included lower postrepair RV:aortic pressure ratio and larger original conduit size.

Conclusions: We were able to obtain follow-up data for the majority of patients, which demonstrated freedom from PA reintervention for two thirds of patients. The time course of and risk factors for conduit reintervention in this cohort appeared similar to previously reported findings in patients who received RV-PA conduits in early childhood for other anomalies. Relative to the severity of baseline pulmonary vascular anatomy in TOF with MAPCAs, reinterventions on the reconstructed PAs were uncommon after repair according to our approach, and major reinterventions were rare. Nevertheless, PA reinterventions are an important aspect of the overall management strategy. (J Thorac Cardiovasc Surg 2018;155:1696-707)

From the Departments of ${ }^{\mathrm{a}}$ Pediatrics, ${ }^{\mathrm{b}}$ Anesthesia, and ${ }^{\mathrm{c}}$ Cardiothoracic Surgery, Clinical and Translational Research Program, Lucile Packard Children's Hospital Heart Center, Stanford University School of Medicine, Palo Alto, Calif.

The IRB protocol number is 26082 and the original IRB approval date was December 11, 2012.

Received for publication April 30, 2017; revisions received Nov 9, 2017; accepted for publication Nov 19, 2017; available ahead of print Jan 17, 2018

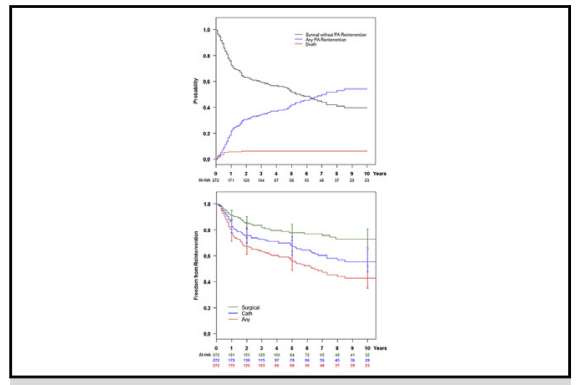

Freedom from pulmonary artery reintervention after complete repair.

\section{Central Message}

Relative to the severity of baseline pulmonary vascular anatomy in TOF with MAPCAs, reinterventions on the reconstructed PAs were relatively uncommon after repair according to our approach.

\section{Perspective}

Our institutional approach to TOF with MAPCAs emphasizes unifocalization and augmentation of the reconstructed pulmonary arterial (PA) circulation and complete intracardiac repair. This retrospective analysis reveals conduit reinterventions appeared similar to previously reported findings in patients with RVPA homografts and PA reinterventions are relatively uncommon given the complexity of baseline PA anatomy.

See Editorial Commentary page 1708.

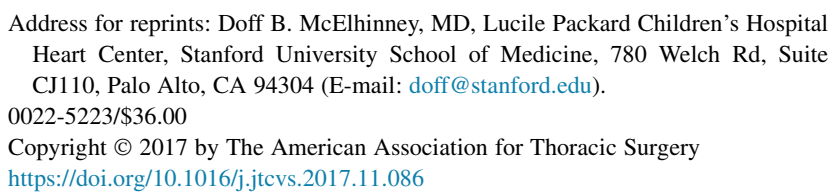

Address for reprints: Doff B. McElhinney, MD, Lucile Packard Children's Hospital Heart Center, Stanford University School of Medicine, 780 Welch Rd, Suite CJ110, Palo Alto, CA 94304 (E-mail: doff@stanford.edu). $0022-5223 / \$ 36.00$

Copyright (C) 2017 by The American Association for Thoracic Surgery https://doi.org/10.1016/j.jtcvs.2017.11.086 


$$
\begin{aligned}
& \text { Abbreviations and Acronyms } \\
& \begin{aligned}
\text { MAPCAs = } & \text { major aortopulmonary collateral } \\
& \text { arteries } \\
\text { PA } & \text { pulmonary artery } \\
\text { RV } & \text { right ventricle } \\
\text { RVOT }= & \text { right ventricular outflow tract } \\
\text { TOF } & =\text { tetralogy of Fallot } \\
\text { VSD } & =\text { ventricular septal defect }
\end{aligned}
\end{aligned}
$$

Scanning this QR code will take you

to the article title page.

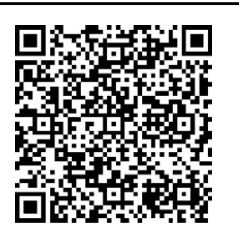

Tetralogy of Fallot (TOF) with major aortopulmonary collateral arteries (MAPCAs) is a complex congenital heart anomaly with variable anatomy. Our institutional approach to this lesion at Lucile Packard Children's Hospital Stanford has emphasized early repair, with complete unifocalization and augmentation of the reconstructed pulmonary artery (PA) circulation, closure of the ventricular septal defect (VSD), and placement of a valved right ventricle (RV)-to-PA conduit, usually in a single procedure. ${ }^{1-5}$

The majority of patients with TOF, pulmonary valve atresia or severe stenosis, and MAPCAs who undergo initial management at our center are able to have a single-stage complete unifocalization and repair consisting of complete unifocalization and reconstruction of the pulmonary circulation, closure of the VSD, and placement of a valved RV-to-PA homograft conduit. Similarly, most patients referred to our center after previous procedures elsewhere undergo complete repair or revision of a previous repair as the first operation at our institution. Among patients palliated at our center, either primarily or after procedures elsewhere, most subsequently undergo complete repair.

Among the entire cohort of patients managed at our center, the probability of complete repair is $83 \% 1$ year after the initial surgery at our center and $93 \%$ at 5 years. ${ }^{1}$ In a subset of patients, palliative approaches leading to staged unifocalization and repair are used, depending on the anatomy and physiology of the pulmonary circulation. Regardless of the initial approach, the ultimate goal is to achieve a separated circulation with incorporation of all lung segments, elimination of PA obstruction out to the segmental level, and low RV pressure. We previously reported that patients managed according to our programmatic approach generally have low RV pressures immediately after unifocalization and repair. ${ }^{1}$ However, little is known about remodeling of the unifocalized and reconstructed pulmonary circulation or about surgical or transcatheter reinterventions on the reconstructed PAs or the right ventricular outflow tract (RVOT) conduit.

Our approach to evaluation and management after complete unifocalization and repair is to perform or recommend close follow-up with serial quantitative lung perfusion scans and echocardiograms for the first 12 months and catheterization approximately 1 year after repair, unless imaging/clinical evaluation dictates earlier catheterization. The purpose of this intensive schedule during the first year after surgery is prompt identification of RV pressure elevation and/or lateral or regional changes in pulmonary perfusion. Taken together, these findings should identify significant uni- or bilateral PA obstruction during the time frame when we believe the risk of adverse remodeling is greatest. The 1-year catheterization is intended to provide a direct evaluation of the reconstructed PA anatomy, including measurement of both proximal and distal PA pressures. We secondarily intervene on even modest stenoses, with a goal of maintaining systolic PA pressures as low as possible. If there are multiple PA stenoses and central PA pressures exceed half systemic pressure after balloon angioplasty, surgical reintervention is typically recommended. How often and how extensive these reinterventions are necessary has not been established. Thus, the current study was performed to characterize time-related outcomes related to reintervention on the RVOT or PAs after complete repair of TOF with MAPCAs in infants and young children, as well as risk factors for shorter freedom from reintervention.

\section{METHODS \\ Patients}

A retrospective chart review from November 2001 through March of 2016 was performed on patients with TOF and MACPAs who underwent complete repair (including unifocalization and PA reconstruction, VSD closure, and RVOT conduit placement) at less than 2 years of age, either in a single-stage or after palliation at our center or elsewhere. The study cohort was limited to this younger cohort for a combination of reasons: (1) our institutional strategy is to perform complete repair at an early age, and a large majority of patients are infants or children $<2$ years of age; and (2) preliminary exploratory analysis demonstrated that the probability of both PA and RV-PA conduit reintervention was substantially greater among the subgroup of patients who underwent complete repair at $<2$ years of age. Our approach to repair and outcomes in our entire cohort were detailed in a recent report. ${ }^{1}$

The native anatomy of the PAs and MAPCAs could not always be ascertained for patients who underwent surgery elsewhere before referral to our center, so it was not possible to assess potential relationships between these anatomic features and outcomes in those patients. Native anatomic features analyzed included pulmonary valve atresia versus severe stenosis, the presence of confluent central PAs, unilateral PA supply from a ductus arteriosus, and the number of MAPCAs unifocalized.

\section{Reinterventions}

There were no standardized criteria for when or how to intervene after repair. Our institutional approach to TOF with MAPCAs is predicated on 
the belief that the reconstructed pulmonary circulation should incorporate all pulmonary segments if possible, to maintain the lowest possible RV (central PA) pressure. These premises apply both to the initial surgical reconstruction and to the management of residual or recurrent PA stenoses after complete repair. Thus, we have a relatively low threshold for reintervention on the reconstructed PA circulation with balloon angioplasty, although we prefer to avoid stents and will go back for surgical PA revision if there are untreatable or multifocal lesions and a systolic PA pressure above $50 \%$ of the systemic pressure after catheter intervention.

For this study, we recorded all postrepair interventions on the pulmonary circulation, including transcatheter angioplasty or stenting of the conduit or PA, surgical PA revision of any type, surgical conduit replacement or revision, and transcatheter pulmonary valve replacement. We included interventions performed at our institution or elsewhere, with hemodynamic and procedural information when available, although we did not always have access to details regarding outside procedures. RV:aortic or PA:aortic pressure ratios were obtained at the time of most recent cardiac catheterization at follow-up. Although, by definition, PA interventions were for obstruction and improvement of perfusion homogeneity, no attempt was made to distinguish or analyze precise clinical or anatomic indications for reintervention, which are not always clearly stated and can be multifactorial. PA interventions were characterized as proximal if they involved only the branches proximal to the origin of the first lobar or segmental vessel. Interventions on lobar or segmental branches were categorized as distal. PA interventions were characterized as unilateral or bilateral. For the purposes of analysis, surgical and transcatheter interventions were also combined and analyzed as "any reintervention."

\section{Data Analysis}

Data are presented as number $(\%)$ for categorical variables and as median (quartile 1-quartile 3) for continuous variables. Comparison of categorical baseline variables between groups was performed with the $\chi^{2}$ or the Fisher exact test. Nonparametric comparison of continuous variables was performed with the Wilcoxon rank sum test or the Kruskal-Wallis test. Timerelated outcomes after complete repair, including freedom from surgical or transcatheter reintervention (combined as "any reintervention") on the reconstructed PAs or RV-PA conduit, are depicted graphically with KaplanMeier curves, with $95 \%$ confidence intervals calculated based on the "log" scale. Assessment of factors associated with time-related outcomes was performed with log-rank testing and Cox proportional hazards regression analysis. Competing outcomes curves and cumulative incidence estimates were produced for the outcomes death, any PA reintervention, and survival without PA reintervention. When indicated, factors significant at the .05 level in univariable analysis were considered for inclusion in multivariable Cox regression models, which were run with forward-stepwise selection. $P$ values $<.05$ were considered significant. Cases with missing data were excluded from analysis on a case-wise basis. $\mathrm{R}$ version 3.3.1 ( $\mathrm{R}$ Foundation for Statistical Computing, Vienna, Austria) and SPSS, version 23 (IBM Corp, Armonk, NY) were used for statistical analysis.

This retrospective study was performed in accordance with a protocol approved by the Institutional Review Board at Stanford University, with a waiver of informed consent.

\section{RESULTS \\ Patients}

In our retrospective review of 272 patients, the median age at repair was 6.2 months, and most patients were infants. Of the cohort, $19 \%$ of patients $(n=52)$ had undergone some form of surgery before the first procedure at our center. Overall, complete single-stage unifocalization and repair was performed in $61 \%$ of patients, and among the 220 patients who did not have surgery before referral
TABLE 1. Baseline and outcome data among 272 patients undergoing complete repair of TOF with MAPCAs during the first 2 years of life

\begin{tabular}{lc}
\hline & $\begin{array}{c}\text { Total } \\
\mathbf{N}=\mathbf{2 7 2}\end{array}$ \\
\hline Male & $140(52 \%)$ \\
Age at complete repair, mo & $6.2(4.2-10.7)$ \\
Weight at complete repair, kg & $6.0(5.0-7.6)$ \\
Known genetic abnormality & \\
$\quad$ Deletion chromosome 22q11 & $111(41 \%)$ \\
$\quad$ Alagille syndrome & $5(2 \%)$ \\
Native anatomy & \\
$\quad$ Valvar pulmonary stenosis (all others atresia) & $25(9 \%)$ \\
$\quad$ Confluent central PAs & $196(75 \%)$ \\
$\quad$ PDA supplying one lung & $27(10 \%)$ \\
Surgery before LPCHS & $52(19 \%)$
\end{tabular}

First surgery at LPCHS

Single-stage complete unifocalization and repair $165(61 \%)$

Unifocalization to shunt or other palliation $\quad 41(15 \%)$

Aortopulmonary window

$32(12 \%)$

Complete repair or revision unifocalization $\quad 34(13 \%)$ after previous surgery

Procedural details

Homograft conduit diameter, $\mathrm{mm}$

$15(12-17)$

Number of MAPCAs unifocalized

$4(2-5)$

Duration of cardiopulmonary bypass, min

$250(188-320)$

Early postrepair systolic RV pressure, $\mathrm{mm} \mathrm{Hg}$

$35(29-38)$

RV:Ao systolic pressure ratio

$0.36(0.30-0.41)$

Postoperative duration of intensive care unit stay, d 9 (6-16)

Postoperative duration of hospitalization, $\mathrm{d}$

$15(10-22.5)$

Data presented as frequency (\% of total) or median (quartile 1-quartile 3). $P A$, Pulmonary artery; PDA, patent ductus arteriosus; LPCHS, Lucile Packard Children's Hospital Stanford; MAPCAs, major aortopulmonary collateral arteries; $R V$, right ventricle; $A o$, aortic.

to our center, $75 \%$ underwent complete single-stage unifocalization and repair. Demographic and procedural data are summarized in Table 1. RV-to-PA conduits were valved aortic or pulmonary homografts, with a median diameter of $15 \mathrm{~mm}$ at the time of implant (Table 1).

Follow-up data were obtained at a median of 3.6 years after complete repair (quartiles 1-3: 0.9-8.0, maximum: 14.4, mean: 4.6), and were available within 3 years in all but 30 surviving patients $(88 \%)$. There were 20 deaths, 6 of which were in the early postoperative period after complete repair $(2.2 \%)$. Among the 252 survivors, the median follow-up was 3.9 years after complete repair (quartiles 1-3: 1.3-8.7, maximum: 14.4, mean: 4.9). The median RV (or PA) to aortic pressure ratio on most recent follow-up evaluation (with catheterization, $\mathrm{n}=104$, or echocardiogram if no catheterization) was $0.39(0.32-0.50)$, and was $>0.6$ in 7 patients.

\section{Reinterventions}

Reinterventions on the pulmonary circulation (RVOT, PAs, and residual MAPCAs) were performed in 134 
TABLE 2. Interventions on the pulmonary circulation after complete repair

\begin{tabular}{cc}
\hline Intervention & No. patients (\%) \\
\hline Any RVOT or PA intervention & $134(49)$ \\
Conduit interventions & $101(37)$ \\
Conduit replacement & $83(31)^{*}$ \\
Transcatheter pulmonary valve replacement & $27(10) \dagger$ \\
Conduit angioplasty or stenting & $10(4) \dagger$ \\
Branch pulmonary artery interventions & $101(37)$ \\
Surgical PA interventions & $46(17)$ \\
Proximal PA arterioplasty only & $18(7)$ \\
Unilateral & $10(4)$ \\
Bilateral & $8(3)$ \\
Distal PA arterioplasty (with or & $28(10)$ \\
without proximal) & \\
Unilateral & $15(6)$ \\
Bilateral & $13(5)$ \\
Transcatheter PA interventions & $75(28)$ \\
Proximal PA intervention & $30(11)$ \\
Unilateral & $20(7)$ \\
Bilateral & $10(4)$ \\
Distal PA intervention & $50(18)$ \\
Unilateral & $30(11)$ \\
Bilateral & $20(7)$ \\
Residual MAPCAs embolized & $9(3)$ \\
\hline
\end{tabular}

RVOT, Right ventricular outflow tract; PA, pulmonary artery; MAPCAs, major aortopulmonary collateral arteries. ${ }^{*}$ Conduit replacement was the first conduit intervention in 77 patients and was performed after previous conduit angioplasty/ stenting in 6 . †Melody valve was first conduit reintervention in 14 patients and after previous conduit replacement in 13 . †् Conduit angioplasty/stenting was followed by Melody valve implant $(\mathrm{n}=1)$ and/or surgical conduit replacement $(\mathrm{n}=2)$ in 6 patients.

patients, as detailed in Table 2, including conduit interventions in 101 patients, branch PA interventions in 101, and closure of residual collaterals in 8. These collaterals were either acquired collaterals or dual supply and did not represent a sole source of pulmonary blood flow. Most of these patients $(n=48)$ had a single intervention, whereas 16 had 2 and 9 had 3 or more. The median RV (or PA) to aortic pressure ratio in patients who had multiple PA interventions was 0.40 , with only $1>0.6$. Conduit reinterventions. Conduit reinterventions were performed in 101 patients. The first intervention consisted of surgical conduit replacement in 77 patients, transcatheter pulmonary valve replacement with a Melody valve in 14 , and conduit angioplasty or bare metal stenting in 10 . Of the 10 conduits initially treated with angioplasty or stenting, 8 were within 4 years of repair, 8 were $14 \mathrm{~mm}$ or smaller at implant, and 6 were subsequently replaced surgically a median of 3.3 years later (0.4-8.8). The 14 patients who underwent transcatheter pulmonary valve replacement, including 10 whose original conduit diameter was $16 \mathrm{~mm}$ or smaller, were all free from subsequent reintervention a median of 1.2 years later. Among 18 patients with an original conduit that was $15 \mathrm{~mm}$ or larger who underwent a first conduit reintervention after transcatheter pulmonary valve replacement was introduced in 2010, one half received a Melody valve (Medtronic, Minneapolis, Minn) and one half had surgical conduit replacement ( 6 of the 9 who underwent conduit replacement also had surgical PA arterioplasty). In addition to the 14 patients who underwent Melody valve implant as a first conduit reintervention, 13 others whose first conduit reintervention was surgical replacement underwent transcatheter pulmonary valve replacement of the second conduit a median of 6 years later (1.9-10).

Freedom from any conduit reintervention $(58 \pm 8 \%$ at 5 years) and freedom from surgical conduit replacement (64 $\pm 7 \%$ at 5 years) are depicted in Figure 1. Factors associated with these outcomes on univariable analysis included age and weight at the time of repair, conduit size, and early postrepair RV:aortic pressure ratio. On multivariable Cox regression analysis, only larger conduit size was associated with longer freedom from conduit reinterventions, although lower early post-repair RV:aortic pressure ratio was also significantly associated with longer freedom from the combined outcome of surgical or transcatheter replacement (Figure 1 and Table 3).

Reinterventions on the PAs. As summarized in Table 2, a total of 101 patients underwent reinterventions on the reconstructed PA circulation, 42 of whom had procedures on both the left and right PAs. Surgical PA reinterventions were performed in 46 patients and transcatheter reinterventions in 75 (20 of these patients had both). All but a few of the surgical PA reinterventions and 44\% of transcatheter reinterventions were performed at our center.

Freedom from any PA reintervention was $43 \pm 8 \%$ at 10 years, as depicted in Figure 2. The steepest hazard was during the first year, and on landmark analysis of patients who were alive and reintervention-free 1-year postrepair, freedom from subsequent PA reintervention was $54 \pm 8 \%$ at 10 years after repair. Factors associated with longer freedom from any PA reintervention on multivariable analysis included lower postrepair RV:aortic pressure ratio (Figure 3) and larger original conduit size (Table 4). These results were unchanged when the analysis excluded 15 patients whose only PA reintervention was surgical arterioplasty limited to the proximal PAs concomitant with conduit replacement.

Surgical reintervention on the PAs was performed in 46 patients (Table 2). In 35 of these patients, PA reinterventions were performed during the same operation as a conduit replacement, and in 15 of these cases the only surgical PA reintervention was proximal PA arterioplasty at the time of conduit replacement. Surgical reinterventions included arterioplasty of 1 or more vessels beyond the origin of the first lobar branch (distal) in 28 patients, with or without more proximal work, and proximal arterioplasty 

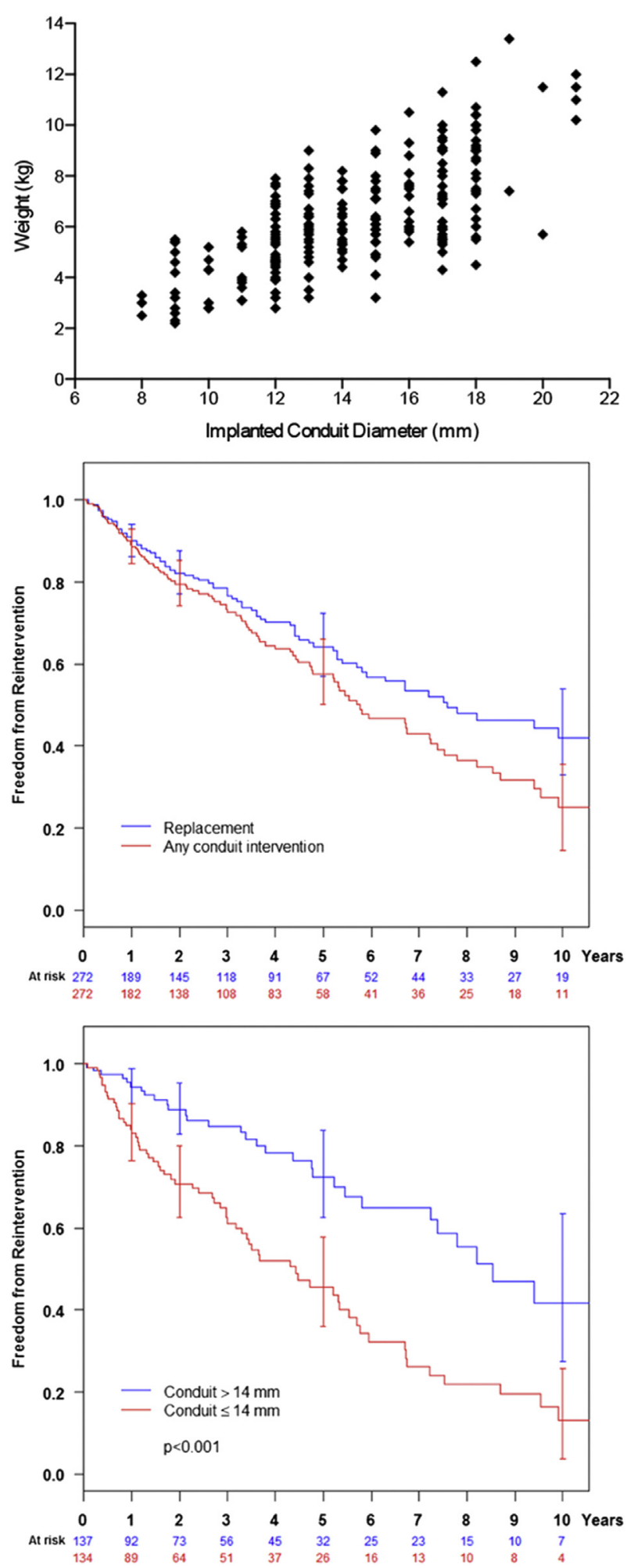

FIGURE 1. Top, Scatterplot demonstrates the distribution of implanted RV-to-PA conduit diameters according to patient weight at the time of repair. Middle, Kaplan-Meier curves demonstrate freedom from conduit reintervention for the entire cohort, including any reintervention (surgical replacement, transcatheter pulmonary valve replacement, angioplasty, or stenting) and surgical replacement. Bottom, Kaplan-Meier curves demonstrate freedom from any conduit reintervention is depicted for patients with an initial conduit diameter $\leq 14 \mathrm{~mm}$ or $>14 \mathrm{~mm}$. The $P$ value is for $\log$ rank comparison between groups. of 1 or both main PA branches in the other 18. Interventions were unilateral in 25 patients and bilateral in 21.

Freedom from surgical PA reintervention was $77 \pm 7 \%$ at 10 years, as depicted in Figure 2. Similar to the analysis of any PA reintervention, factors associated with longer freedom from surgical PA reintervention included older age (Figure 3) and greater weight at repair, larger conduit size, and lower RV pressure (Table 4). On multivariable Cox regression, lower postrepair RV:aortic pressure ratio and larger original conduit size remained significant (Table 4).

Catheter-based reintervention on the branch PAs was more frequent than surgical reintervention and was performed during the study period in 75 patients, with distal interventions more common than interventions on the proximal branches (Figure 4). Overall, 26 patients underwent multiple postrepair catheterizations with PA interventions, 9 of whom had 3 more reintervention procedures. The median number of vessels treated was 1 (1-6), and only 14 patients had intervention on more than 2 branches (Figure 5). Reinterventions on both left and right PA branches were performed in 26 patients. Stents were implanted in 15 patients.

Overall, freedom from transcatheter PA reintervention was $56 \pm 8 \%$ at 10 years. Among patients who had not undergone PA reintervention during the first postrepair, freedom from transcatheter reintervention at 5 years was $80 \pm 6 \%$. Factors associated with shorter freedom from transcatheter PA reintervention included greater early postrepair RV:aortic pressure ratio and smaller conduit diameter but also a larger number of unifocalized MAPCAs (Figure 3).

Eight patients underwent transcatheter closure of residual MAPCAs, which were generally small and either acquired or dual-supply, all but 1 within a year of repair. Five of these patients had undergone an aortopulmonary window as a first procedure, and 4 had transcatheter PA reinterventions during the same catheterization.

\section{DISCUSSION}

\section{TOF With MAPCAs}

TOF with MAPCAs is among the most complicated and heterogeneous forms of congenital heart disease. The anatomy of pulmonary blood supply is highly variable, ${ }^{6,7}$ and approaches to management are just as diverse. ${ }^{8-21}$ In part because of this variability, there is limited basis for objective comparison of outcomes, particularly long-term outcomes, between different strategies. Although a number of investigators have described their experience in patients with TOF and MAPCAs, ${ }^{10-21}$ usually with a focus on the staging or repair sequence and survival, there has been little attention to reinterventions on the pulmonary circulation. In contrast to most other forms of complex congenital heart disease, the incidence and relevance of 
TABLE 3. Results of uni- and multivariable analysis of factors associated with conduit reintervention

\begin{tabular}{|c|c|c|c|c|}
\hline Variable & $\begin{array}{c}\text { Univariable HR } \\
(95 \% \text { CI })\end{array}$ & $P$ value & $\begin{array}{c}\text { Multivariable HR } \\
(95 \% \mathrm{CI})\end{array}$ & $P$ value \\
\hline \multicolumn{5}{|l|}{ Any conduit reintervention } \\
\hline Age, y & $0.40(0.25-0.65)$ & $<.001$ & $1.1(0.6-2.0)$ & .84 \\
\hline Repair $<1$ y of age & $3.2(1.7-5.9)$ & $<.001$ & & \\
\hline Weight, $\mathrm{kg}$ & $0.80(0.71-0.91)$ & .001 & & \\
\hline Chromosome 22q11 deletion & $0.76(0.50-1.18)$ & .22 & & \\
\hline Nonconfluent central PAs & $0.97(0.60-1.54)$ & .88 & & \\
\hline Complete single-stage repair & $1.19(0.79-1.81)$ & .41 & & \\
\hline First surgery performed at LPCHS & $1.16(0.69-1.94)$ & .58 & & \\
\hline No. MAPCAs unifocalized & $0.97(0.86-1.08)$ & .56 & & \\
\hline Implanted conduit diameter, $\mathrm{mm}$ & $0.76(0.70-0.83)$ & $<.001$ & $0.76(0.67-0.85)$ & $<.001$ \\
\hline $\mathrm{CPB}$ duration, min & $1.001(0.99-1.004)$ & .34 & & \\
\hline Postrepair RV:Ao pressure ratio, $\%$ & $1.03(0.99-1.06)$ & .055 & & \\
\hline \multicolumn{5}{|c|}{ Conduit replacement or transcatheter pulmonary valve replacement } \\
\hline Age, $y$ & $0.42(0.25-0.69)$ & .001 & $0.8(0.4-1.5)$ & .49 \\
\hline Repair $<1$ y of age & $2.95(1.57-5.55)$ & .001 & & \\
\hline Weight, $\mathrm{kg}$ & $0.83(0.73-0.94)$ & .004 & & \\
\hline Chromosome $22 \mathrm{q} 11$ deletion & $0.82(0.53-1.25)$ & .4 & & \\
\hline Nonconfluent central PAs & $0.89(0.35-1.44)$ & .89 & & \\
\hline Complete single-stage repair & $1.22(0.80-1.87)$ & .36 & & \\
\hline First surgery performed at LPCHS & $1.28(0.75-2.18)$ & .36 & & \\
\hline No. MAPCAs unifocalized & $0.99(0.88-1.11)$ & .82 & & \\
\hline Implanted conduit diameter, $\mathrm{mm}$ & $0.79(0.73-0.86)$ & $<.001$ & $0.80(0.73-0.87)$ & $<.001$ \\
\hline $\mathrm{CPB}$ duration, min & $1.002(0.99-1.005)$ & .26 & & \\
\hline Postrepair RV:Ao pressure ratio, $\%$ & $1.03(1.00-1.06)$ & .029 & $1.03(1.01-1.06)$ & .016 \\
\hline \multicolumn{5}{|l|}{ Conduit replacement } \\
\hline Age, y & $0.42(0.24-0.72)$ & .002 & $1.1(0.5-2.3)$ & .80 \\
\hline Repair $<1$ y of age & $2.50(1.29-4.86)$ & .007 & & \\
\hline Weight, kg & $0.77(0.66-0.89)$ & $<.001$ & & \\
\hline Chromosome 22q11 deletion & $0.83(0.52-1.35)$ & .45 & & \\
\hline Nonconfluent central PAs & $0.85(0.51-1.42)$ & .53 & & \\
\hline Complete single-stage repair & $1.18(0.75-1.87)$ & .48 & & \\
\hline First surgery performed at LPCHS & $1.24(0.71-2.18)$ & .45 & & \\
\hline No. MAPCAs unifocalized & $1.04(0.92-1.18)$ & .50 & & \\
\hline Implanted conduit diameter, $\mathrm{mm}$ & $0.78(0.71-0.85)$ & $<.001$ & $0.76(0.69-0.83)$ & $<.001$ \\
\hline $\mathrm{CPB}$ duration, $\min$ & $1.002(0.99-1.005)$ & .18 & & \\
\hline Postrepair RV:Ao pressure ratio, $\%$ & $1.035(1.005-1.065)$ & .021 & $1.03(1.01-1.06)$ & .020 \\
\hline
\end{tabular}

"reintervention" can be somewhat unclear in patients with TOF with MAPCAs, due in part to the prevalence of staged or palliative approaches to treatment in which the need for multiple procedures is intrinsic.

Although complete surgical repair is the thrust of our programmatic management strategy and postoperative transcatheter PA "rehabilitation" is not an integral component as it is at some centers, we maintain a low threshold for transcatheter reintervention, even for modest residual or recurrent $\mathrm{PA}$ obstructions, if it serves the aim of homogenizing segmental PA flow and pressure. Remodeling of the reconstructed PA circulation is not well defined or predictable, and reinterventions after the initial repair can be important steps in achieving the aforementioned management goals. However, we have not previously characterized the incidence rates or risk factors for intervention on the PAs or RVOT after complete repair, which is important information for understanding the pathophysiology of this lesion and for patient/family counseling.

\section{PA Reinterventions}

During the first year after surgery, we recommend frequent assessment of regional PA perfusion and RV pressure and function with quantitative lung perfusion scintigraphy and echocardiography. Then at 1 year, we recommend that all patients undergo diagnostic catheterization with balloon angioplasty, as indicated for amenable 

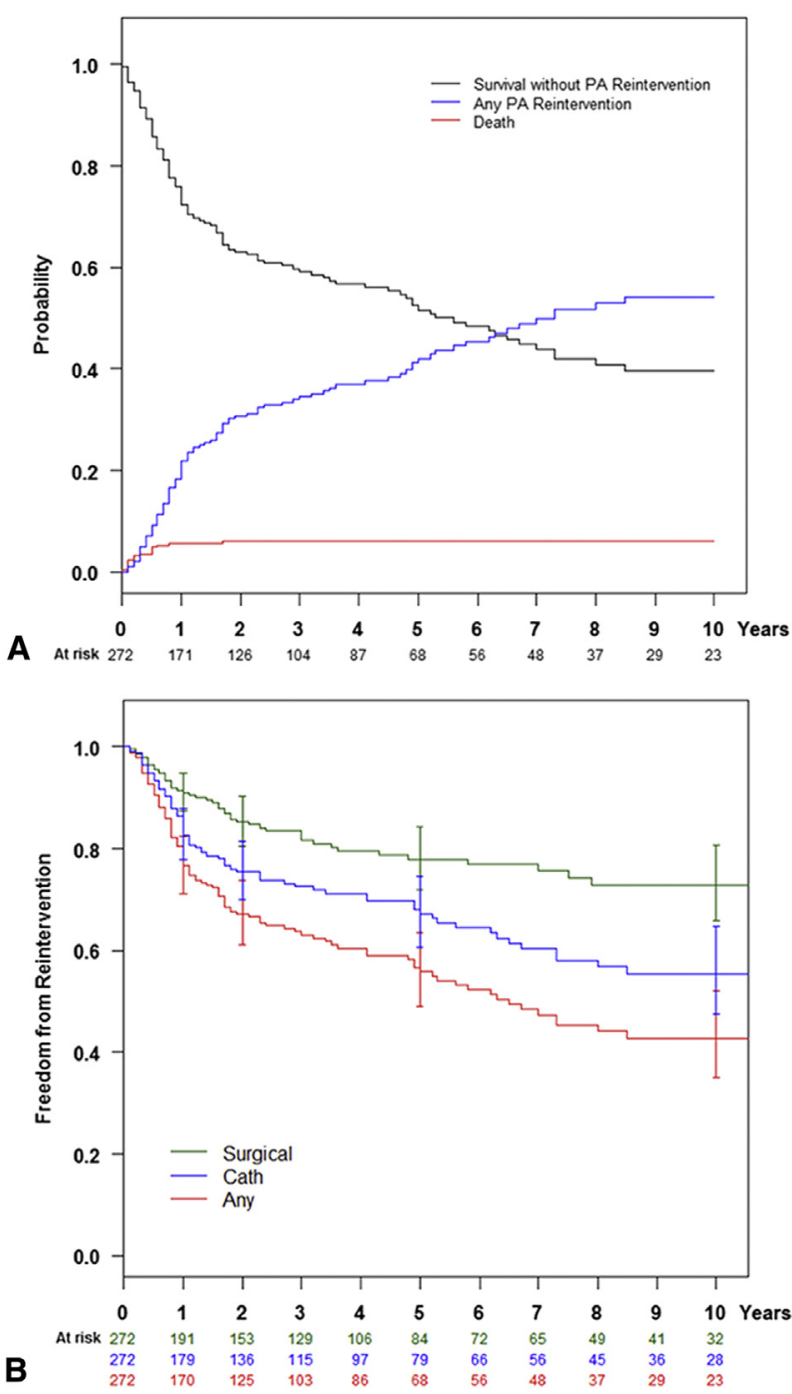

FIGURE 2. A, Competing outcomes curve depicts cumulative probabilities of death, any PA reintervention, and survival free from PA reintervention. B, Kaplan-Meier curves show freedom from any PA reintervention, surgical PA reintervention, and transcatheter PA reintervention from the time of complete repair. $P A$, Pulmonary artery.

stenoses. If there is more extensive obstruction, or geometric abnormalities such as kinking, we prefer surgical revision rather than PA stenting. Thus, postrepair PA reintervention after complete repair of TOF with MAPCAs is not an indication of an ineffective or failed repair.

The low threshold for reintervention in our approach notwithstanding, freedom from PA reintervention was favorable in this cohort, and most patients who underwent postrepair intervention had only a single procedure and a single vessel treated. Only 46 of 266 early survivors underwent surgical PA reintervention. Most of those were performed at the time of conduit reintervention, and one third involved only proximal PA arterioplasty concomitant with conduit replacement. Although a majority of both
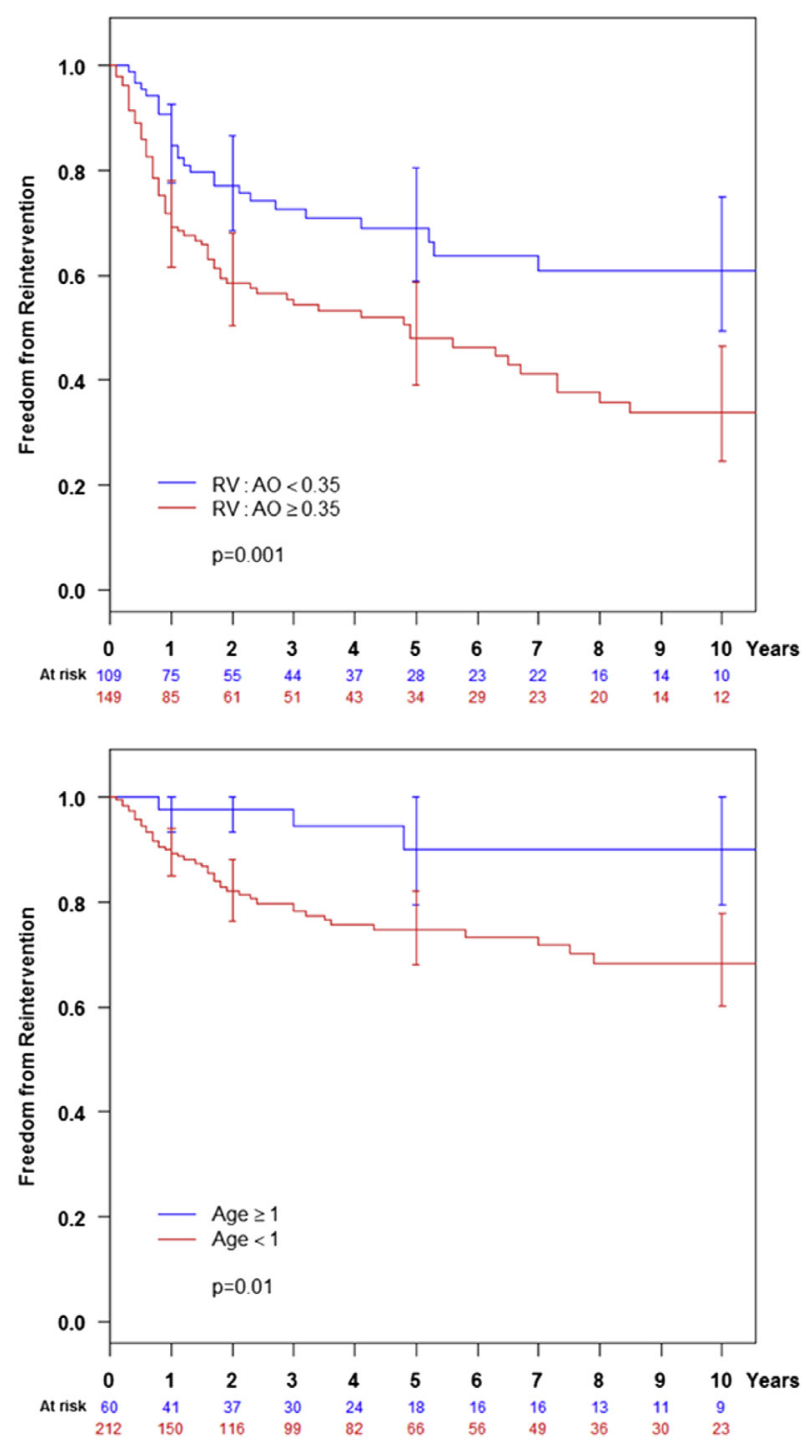

FIGURE 3. Kaplan-Meier curves depict freedom from PA reinterventions. Top, Freedom from any PA reintervention (surgical or transcatheter) according to the early postrepair RV:aortic systolic pressure ratio. Bottom, Freedom from surgical PA reintervention is stratified according to age at repair. The $P$ values are for log rank comparison between groups. $R V$, Right ventricle; $A o$, aortic.

surgical and transcatheter PA reinterventions involved lobar or segmental branches, more than one half were unilateral. This finding is consistent with our observation that the quality of the native PA or MAPCA vasculature is inconsistent, with one lung often worse than the other at the time of repair. Although the specific nature of the recurrent/residual lesions is difficult to categorize and was not ascertained for this study, these findings indicate that extensive surgical PA revision is uncommon after complete repair in this complex population, whose follow-up RV/PA pressures were typically $<40 \%$ of systemic levels. 
TABLE 4. Results of uni- and multivariable analysis of factors associated with PA reintervention

\begin{tabular}{|c|c|c|c|c|}
\hline Variable & Univariable HR $(95 \%$ CI $)$ & $P$ value & Multivariable HR $(95 \%$ CI $)$ & $P$ value \\
\hline \multicolumn{5}{|l|}{ Any PA reintervention } \\
\hline Age, y & $0.57(0.36-0.91)$ & .017 & $0.44(0.25-0.76)$ & .003 \\
\hline Repair $<1$ y of age & $1.6(0.9-2.7)$ & .097 & & \\
\hline Weight, kg & $0.89(0.79-1.00)$ & .050 & & \\
\hline Chromosome $22 \mathrm{q} 11$ deletion & $0.63(0.41-0.97)$ & .035 & & \\
\hline Nonconfluent central PAs & $1.37(0.89-2.12)$ & .16 & & \\
\hline Complete single-stage repair & $0.98(0.66-1.46)$ & .92 & & \\
\hline First surgery performed at LPCHS & $0.95(0.58-1.54)$ & .82 & & \\
\hline No. MAPCAs unifocalized & $1.14(1.01-1.28)$ & .03 & $1.11(0.97-1.27)$ & .11 \\
\hline Implanted conduit diameter, $\mathrm{mm}$ & $0.88(0.82-0.95)$ & .001 & & \\
\hline $\mathrm{CPB}$ duration, min & $1.003(1.000-1.005)$ & .048 & & \\
\hline Postrepair RV:Ao pressure ratio, $\%$ & $1.05(1.02-1.08)$ & $<.001$ & $1.05(1.03-1.09)$ & $<.001$ \\
\hline \multicolumn{5}{|l|}{ Surgical PA reintervention } \\
\hline Age, $y$ & $0.29(0.12-0.67)$ & .004 & $0.50(0.18-1.44)$ & .20 \\
\hline Repair $<1$ y of age & $4.1(1.3-13.1)$ & .019 & & \\
\hline Weight, kg & $0.78(0.65-0.94)$ & .009 & & \\
\hline Chromosome $22 q 11$ deletion & $0.65(0.34-1.23)$ & .19 & & \\
\hline Nonconfluent central PAs & $1.47(0.80-2.73)$ & .22 & & \\
\hline Complete single-stage repair & $1.17(0.64-2.15)$ & .61 & & \\
\hline First surgery performed at LPCHS & $1.37(0.61-3.07)$ & .44 & & \\
\hline No. MAPCAs unifocalized & $1.01(0.85-1.19)$ & .96 & & \\
\hline Implanted conduit diameter, $\mathrm{mm}$ & $0.80(0.72-0.90)$ & $<.001$ & $0.82(0.72-0.92)$ & .002 \\
\hline CPB duration, min & $1.001(0.97-1.004)$ & .81 & & \\
\hline Postrepair RV:Ao pressure ratio, $\%$ & $1.07(1.02-1.11)$ & $<.001$ & $1.07(1.01-1.11)$ & .001 \\
\hline \multicolumn{5}{|l|}{ Transcatheter PA reintervention } \\
\hline Age, $y$ & $0.70(0.42-1.18)$ & .18 & & \\
\hline Repair $<1$ y of age & $1.18(0.66-2.11)$ & .57 & & \\
\hline Weight, kg & $0.93(0.82-1.06)$ & .29 & & \\
\hline Chromosome 22q11 deletion & $0.56(0.34-0.94)$ & .028 & & \\
\hline Nonconfluent central PAs & $1.34(0.84-2.20)$ & .21 & & \\
\hline Complete single-stage repair & $1.03(0.65-1.64)$ & .91 & & \\
\hline First surgery performed at LPCHS & $0.94(0.54-1.64)$ & .83 & & \\
\hline No. MAPCAs unifocalized & $1.21(1.06-1.39)$ & .005 & $1.26(1.05-1.51)$ & .011 \\
\hline Implanted conduit diameter, $\mathrm{mm}$ & $0.90(0.83-0.98)$ & .020 & $0.89(0.80-0.99)$ & .031 \\
\hline $\mathrm{CPB}$ duration, min & $1.004(1.001-1.007)$ & .013 & & \\
\hline Postrepair RV:Ao pressure ratio, $\%$ & $1.03(1.00-1.06)$ & .029 & $1.05(1.02-1.09)$ & .003 \\
\hline
\end{tabular}

In keeping with our approach of maintaining close surveillance for at least 12 months after repair, and with our expectation that the risk of postrepair PA remodeling would be greatest in the near term after unifocalization and reconstruction, the hazard for PA reintervention was steepest during the first year. The nature, extent, and clinical indications for PA reinterventions varied in these patients, and it is challenging to devise a single outcome metric that encapsulates that diversity. Patients with a greater early postrepair RV:aortic pressure ratio were more likely to undergo PA reintervention. These patients tended to have more complex or hypoplastic distal PA anatomy, and the clinical threshold for reintervention was likely lower, given that RV pressures were greater from the time of repair. Transcatheter PA reinterventions were also associated with a larger number of unifocalized MAPCAs, which suggests that patients who undergo more extensive PA reconstruction are more likely to develop stenosis, which is not surprising simply from a stochastic standpoint. Although it would be useful to identify anatomic features or locations that are more or less prone to recurrent stenosis, we did not always have angiographic images available from outside institutions to make these often complex assessments. Our analysis therefore limited to more general characterizations to reflect the extent of disease requiring reintervention.

\section{Conduit Reintervention}

This study confirms that the timing and risk factors for conduit reintervention in a complex cohort of patients 


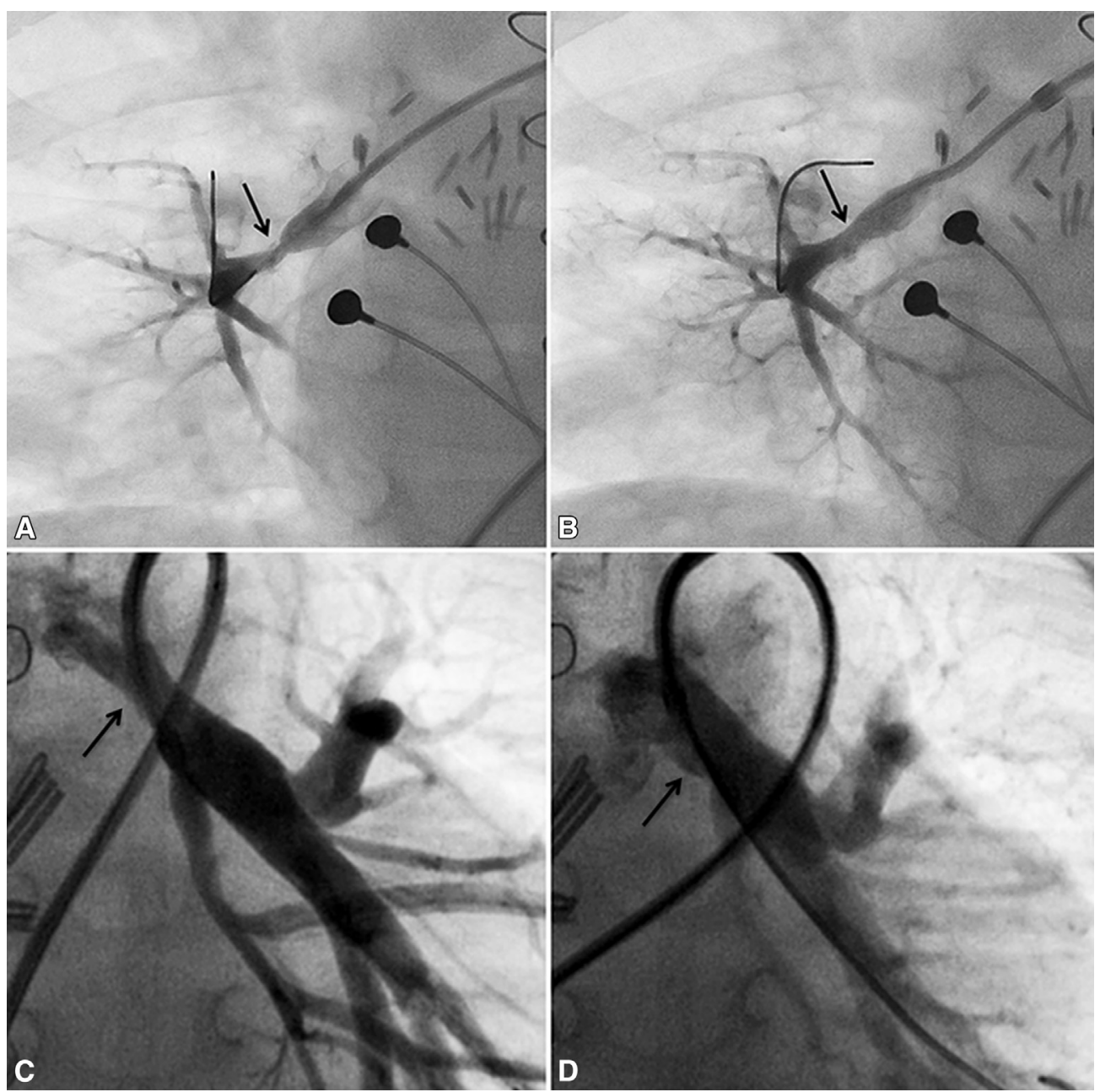

FIGURE 4. Angiograms from 2 different patients who underwent transcatheter balloon angioplasty on a single distal (A) or proximal (B) PA branch after complete repair. A and B, Right middle PA stenosis that was the only vessel dilated in this patient. C and D, Isolated proximal left PA stenosis that was dilated successfully in a different patient. Arrows indicate the stenoses before and after angioplasty.

undergoing early complete repair of TOF with MAPCAs are similar to those for RVOT conduits in infants and young children generally. ${ }^{22-26}$ Although this study did not examine the specific indications for conduit reintervention, there were no unique or concerning trends related to the timing or reintervention. In this cohort, we used valved homograft conduits to establish RV-PA connection at the time of repair, with a median diameter of $15 \mathrm{~mm}$ and most between 12 and $17 \mathrm{~mm}$. Predictably, the predominant risk factor for shorter freedom from reintervention was smaller conduit size. However, because conduit diameter ranged so widely, the type and goals of reintervention varied somewhat across the cohort. For example, in 10 patients, most with small homografts, the initial conduit reintervention was simple angioplasty or stenting for stenosis within several years of repair; 6 of those patients ultimately had conduit replacement a median of 3.3 years later. Although angioplasty is typically of modest benefit for treating RVOT conduits, this limited cohort supports previous reports ${ }^{27}$ that bare metal stenting of small conduits can relieve obstruction and delay surgical replacement by several years.

One of the notable observations related to conduit procedures was that transcatheter pulmonary valve replacement has impacted the reintervention profile for these patients. Since the Melody valve became commercially available in $2010,{ }^{28,29}$ one half of the conduit replacements in patients with an initial conduit diameter $15 \mathrm{~mm}$ or larger were with a Melody valve. Most the remaining cases of conduit replacement were combined with surgical PA reintervention. Although this study did not comprehensively evaluate second conduit reinterventions, it was notable that among 77 patients who had undergone initial surgical conduit replacement, 13 had a transcatheter pulmonary valve implanted a median of 6 years later. There have been no reinterventions after 

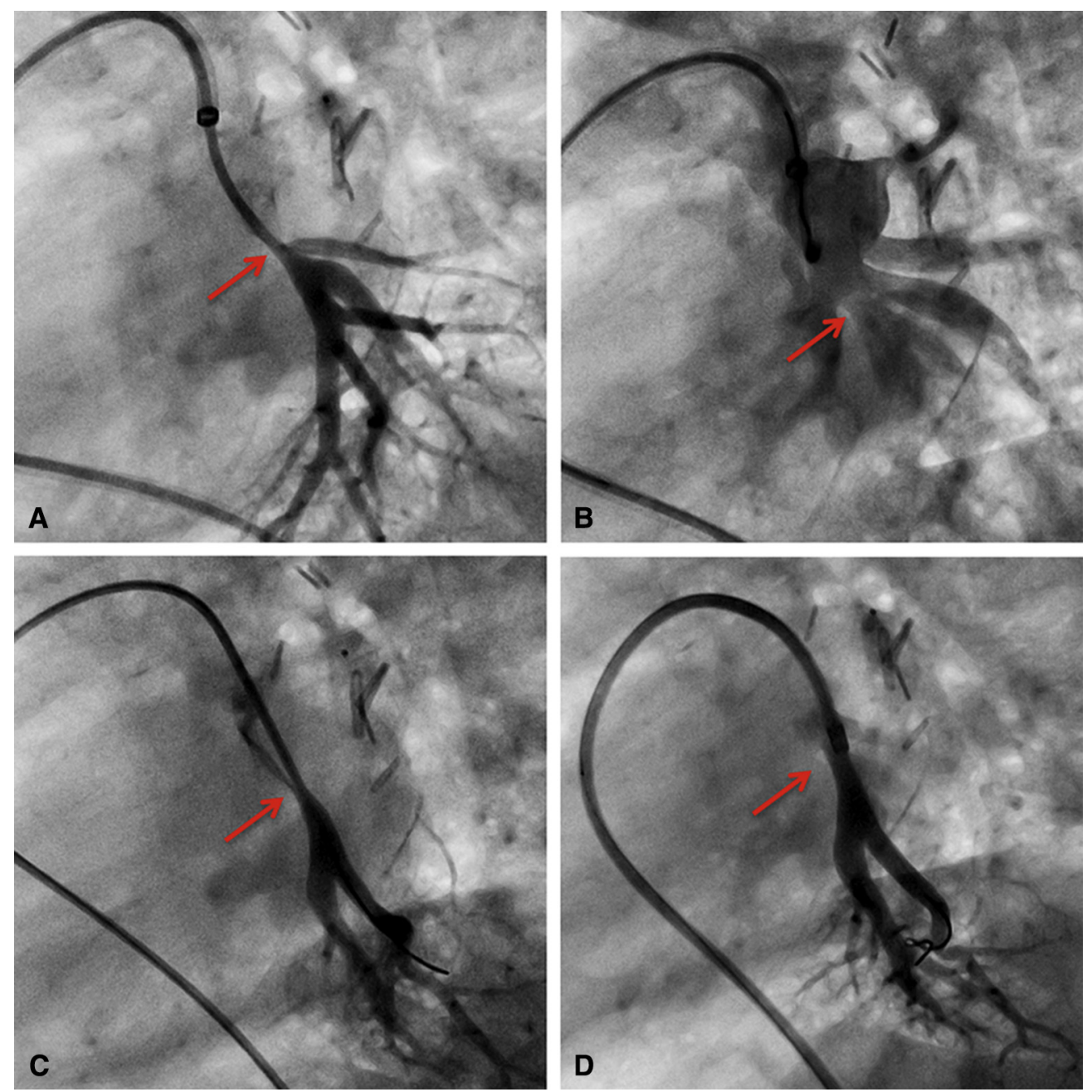

FIGURE 5. These lateral projection angiograms demonstrate multiple right lower PA stenoses in the same patient that were treated successfully with balloon angioplasty. A and B, Pre- and postangioplasty images of the stenosis indicated with the arrows in (A and B). Similarly, the angiograms in (C) and (D) are before and after angioplasty of the stenosis indicated with the arrows in (C and D).

transcatheter pulmonary valve replacement, and the role it will play in this population is still evolving, but it appears to be a promising means of extending conduit lifespan and potentially reducing the lifetime burden of surgery in these complex patients.

\section{Limitations}

This study was subject to the well-established limitations of a retrospective design and to suboptimal access to follow-up data for many patients who were followed elsewhere. Moreover, because of the complexity and variability of PA and MAPCA anatomy, and the lack of a standard nomenclature for categorizing baseline and reconstructed anatomy, many of the potentially important factors that might be risk factors for reintervention could not be ascertained. In addition, this study was complicated by the fact that most of the patients were primarily followed elsewhere after repair, so decision-making about reinterventions, particularly in the catheterization lab, were not standardized. With respect to PA obstruction, there may be variable thresholds for intervening on minor branch stenoses depending on other factors, so all reported interventions were not necessarily of equivalent clinical relevance.

Given a large referral base, many of the patients involved in this study are outside of the catchment area, and therefore strict adherence to the prescribed follow-up protocol is not always possible. Although this study did obtain RV pressures and interventions performed, we were not able to obtain an adequate number of simultaneous, or near-simultaneous, RV pressure by cardiac catheterization and echocardiogram for proper correlation.

\section{CONCLUSIONS}

Reinterventions on the pulmonary circulation were relatively uncommon after repair of TOF with MAPCAs 
according to our approach. However, they are an important aspect of the overall management strategy and are more common during the first 1 to 2 years after repair. Most patients who underwent PA reintervention had only a single vessel treated, indicating that most reinterventions were for relatively minor disease, given the underlying anatomic complexity, and did not necessarily signify major residual or recurrent stenosis. RV pressures were typically low in this cohort, even in those who underwent more than $1 \mathrm{PA}$ reintervention during follow-up. Patients with greater postrepair RV pressure were more likely to undergo PA reintervention, and transcatheter reinterventions were more common in patients who had more MAPCAs unifocalized. However, absence of confluent central PAs and initial surgical strategy were not related to the risk of reintervention. RVOT reintervention after repair of TOF with MAPCAs was common, as it is with other anomalies repaired with conduits early in life, and was associated with smaller conduit size and greater postrepair RV pressure. The introduction of transcatheter pulmonary valve therapy has altered the reintervention profile in this patient population, even in small patients, ${ }^{30}$ and more follow-up and focused investigation will be necessary to gauge the impact of this evolution.

\section{Conflict of Interest Statement}

Authors have nothing to disclose with regard to commercial support.

\section{References}

1. Bauser-Heaton H, Borquez A, Han B, Ladd M, Asija R, Downey L, et al. Programmatic approach to management of tetralogy of Fallot with major aortopulmonary collateral arteries: a 15 -year experience with 458 patients. Circ Cardiovasc Interv. 2017;10:e004952.

2. Malhotra SP, Hanley FL. Surgical management of pulmonary atresia with ventricular septal defect and major aortopulmonary collaterals: a protocolbased approach. Semin Thorac Cardiovasc Surg Pediatr Card Surg Annu. 2009; 145-51.

3. Reddy VM, Liddicoat JR, Hanley FL. Midline one-stage complete unifocalization and repair of pulmonary atresia with ventricular septal defect and major aortopulmonary collaterals. J Thorac Cardiovasc Surg. 1995;109: $832-45$.

4. Reddy VM, McElhinney DB, Amin Z, Moore P, Parry AJ, Teitel DF, et al. Early and intermediate outcomes after repair of pulmonary atresia with ventricular septal defect and major aortopulmonary collateral arteries: experience with 85 patients. Circulation. 2000;101:1826-32.

5. Carrillo SA, Mainwaring RD, Patrick WL, Bauser-Heaton HD, Peng L, Reddy VM, et al. Surgical repair of pulmonary atresia with ventricular septal defect and major aortopulmonary collaterals with absent intrapericardial pulmonary arteries. Ann Thorac Surg. 2015;100:606-13.

6. Shimazaki Y, Maehara T, Blackstone EH, Kirklin JW, Bargeron LM Jr. The structure of the pulmonary circulation in tetralogy of Fallot with pulmonary atresia. A quantitative cineangiographic study. J Thorac Cardiovasc Surg. 1988;95:1048-58.

7. Liao PK, Edwards WD, Julsrud PR, Puga FJ, Danielson GK, Feldt RH. Pulmonary blood supply in patients with pulmonary atresia and ventricular septal defect. J Am Coll Cardiol. 1985;6:1343-50.

8. Boshoff D, Gewillig M. A review of the options for treatment of major aortopulmonary collateral arteries in the setting of tetralogy of Fallot with pulmonary atresia. Cardiol Young. 2006;16:212-20.
9. McElhinney DB, Reddy VM, Hanley FL. Tetralogy of Fallot with major aortopulmonary collaterals: early total repair. Pediatr Cardiol. 1998;19:289-96.

10. Carotti A, Albanese SB, Filippelli S, Ravà L, Guccione P, Pongiglione G, et al. Determinants of outcome after surgical treatment of pulmonary atresia with ventricular septal defect and major aortopulmonary collateral arteries. J Thorac Cardiovasc Surg. 2010;140:1092-103.

11. Davies B, Mussa S, Davies P, Stickley J, Jones TJ, Barron DJ, et al. Unifocalization of major aortopulmonary collateral arteries in pulmonary atresia with ventricular septal defect is essential to achieve excellent outcomes irrespective of native pulmonary artery morphology. J Thorac Cardiovasc Surg. 2009;138:1269-75.

12. Farouk A, Zahka K, Siwik E, Erenberg F, Al-Khatib Y, Golden A, et al. Individualized approach to the surgical treatment of tetralogy of Fallot with pulmonary atresia. Cardiol Young. 2009;19:76-85.

13. Tchervenkov CI, Salasidis G, Cecere R, Béland MJ, Jutras L, Paquet M, et al. One-stage midline unifocalization and complete repair in infancy versus multiple-stage unifocalization followed by repair for complex heart disease with major aortopulmonary collaterals. J Thorac Cardiovasc Surg. 1997;114: 727-37.

14. Iyer KS, Mee RBB. Staged repair of pulmonary atresia with ventricular septal defect and major systemic to pulmonary artery collaterals. Ann Thorac Surg. 1991;51:65-72.

15. Rome JJ, Mayer JE, Castaneda AR, Lock JE. Tetralogy of Fallot with pulmonary atresia. Rehabilitation of diminutive pulmonary arteries. Circulation. 1993;88(4 Pt 1):1691-8.

16. Cho JM, Puga FJ, Danielson GK, Dearani JA, Mair DD, Hagler DJ, et al. Early and long-term results of the surgical treatment of tetralogy of Fallot with pulmonary atresia, with or without major aortopulmonary collateral arteries. J Thorac Cardiovasc Surg. 2002;124:70-81.

17. Duncan BW, Mee RBB, Prieto LR, Rosenthal GL, Mesia CI, Qureshi A, et al. Staged repair of tetralogy of Fallot with pulmonary atresia and major aortopulmonary collateral arteries. J Thorac Cardiovasc Surg. 2003;126: 694-702.

18. D’Udekem Y, Alphonso N, Nørgaard MA, Cochrane AD, Grigg LE, Wilkinson JL, et al. Pulmonary atresia with ventricular septal defects and major aortopulmonary collateral arteries: Unifocalization brings no long-term benefits. J Thorac Cardiovasc Surg. 2005;130:1496-502.

19. Liava'a M, Brizard CP, Konstantinov IE, Robertson T, Cheung MM, Weintraub R, et al. Pulmonary atresia, ventricular septal defect, and major aortopulmonary collaterals: neonatal pulmonary artery rehabilitation without unifocalization. Ann Thorac Surg. 2012;93:185-91.

20. Gupta A, Odim J, Levi D, Chang RK, Laks H. Staged repair of pulmonary atresia with ventricular septal defect and major aortopulmonary collateral arteries: experience with 104 patients. J Thorac Cardiovasc Surg. 2003;126: 1746-52.

21. Zhu J, Meza J, Kato A, Saedi A, Chetan D, Parker R, et al. Pulmonary flow study predicts survival in pulmonary atresia with ventricular septal defect and major aortopulmonary collateral arteries. J Thorac Cardiovasc Surg. 2016;152: 1494-503.

22. Twedell JS, Pelech AN, Frommelt PC, Mussatto KA, Wyman JD, Fedderly RT, et al. Factors affecting longevity of homograft valves used in right ventricular outflow tract reconstruction for congenital heart disease. Circulation. 2000; 102(19 suppl 3):III130-5.

23. Wells WJ, Arroyo H, Bremner RM, Wood J, Starnes VA. Homograft conduit failure in infants is not due to somatic outgrowth. J Thorac Cardiovasc Surg. 2002;124:88-96.

24. Askovich B, Hawkins JA, Sower CT, Minich LL, Tani LY, Stoddard G, et al. Right ventricle-to-pulmonary artery conduit longevity: is it related to allograft size? Ann Thorac Surg. 2007;84:907-11.

25. Karamlou T, Blackstone EH, Hawkins JA, Jacobs ML, Kanter KR, Brown JW, et al; Pulmonary Conduit Working Group for the members of the Congenital Heart Surgeons Society. Can pulmonary conduit dysfunction and failure be reduced in infants and children less than age 2 years at initial implantation? J Thorac Cardiovasc Surg. 2006;132:829-38.

26. Zachariah JP, Pigula FA, Mayer JE Jr, McElhinney DB. Right ventricle to pulmonary artery conduit augmentation compared with replacement in young children. Ann Thorac Surg. 2009;88:574-80.

27. Carr M, Bergersen L, Marshall AC, Keane JF, Lock JE, Emani SM, et al. Bare metal stenting for obstructed small diameter homograft conduits in the right ventricular outflow tract. Catheter Cardiovasc Interv. 2013;81: E44-52. 
28. McElhinney DB, Hellenbrand WE, Zahn EM, Jones TK, Cheatham JP, Lock JE, et al. Short- and medium-term outcomes after transcatheter pulmonary valve placement in the expanded multicenter US melody valve trial. Circulation. 2010;122:507-16.

29. Cheatham JP, Hellenbrand WE, Zahn EM, Jones TK, Berman DP, Vincent JA, et al. Clinical and hemodynamic outcomes up to 7 years after transcatheter pulmonary valve replacement in the US Melody valve investigational device exemption trial. Circulation. 2015;131: 1960-70.
30. Martin MH, Shahanavaz S, Peng LF, Asnes JD, Riley M, Hellenbrand WE, et al Percutaneous transcatheter pulmonary valve replacement in children weighing less than $20 \mathrm{~kg}$. Catheter Cardiovasc Interv. November 29, 2017. [Epub ahead of print].

Key Words: pulmonary atresia, tetralogy of Fallot, pulmonary artery, transcatheter pulmonary valve replacement, balloon angioplasty 